\title{
EL CUARTO BRONCE DE BOTORRITA
}

\author{
Francisco Beltrán Lloris
}

F. Villar, Ma . A. Díaz, M. M ${ }^{\mathrm{a}}$. Medrano y C. Jordán, El IV bronce de Botorrita (Contrebia Belaisca): arqueología y lingüística, Ediciones Universidad de Salamanca, Salamanca 2001, 226 pp.

Con la edición del cuarto bronce de Botorrita queda a disposición de la comunidad científica el último de los epígrafes broncíneos con texto extenso exhumado hasta la fecha en el prolífico yacimiento del Cabezo de las Minas. Pese a tratarse de una inscripción incompleta y de conservación deficiente, en la que apenas resulta legible una veintena de palabras completas - lejos, por lo tanto, de las veinte líneas de texto de Botorrita 1 o de los 240 registros precedidos por dos líneas de encabezamiento de Botorrita 3-, la publicación de Botorrita 4 supone una valiosa contribución al corpus epigráfico celtibérico más allá del interés que entraña por sí misma cualquier ampliación de un catálogo documental tan exiguo como es el hispano-céltico. Ello obedece en buena medida al excelente trabajo realizado por los editores de la inscripción, Francisco Villar y Carlos Jordán (V-J en lo sucesivo), que no sólo han conseguido establecer una sólida versión de un texto epigráfico repleto de dificultades, sino que además han construido una elaborada y sugerente interpretación del mismo que, independientemente del grado de consenso que logre entre los investigadores, tiene la virtud de plantear nuevas perspectivas en el estudio de la excepcional serie epigráfica contrebiense y en particular de Botorrita 1, cuyo texto, como V-J subrayan, presenta notables coincidencias con el del nuevo epígrafe, apreciación que sin duda constituye una de las principales aportaciones del estudio. Con ello la discusión sobre los bronces de Botorrita, que últimamente parecía haber perdido intensidad, se reanima con nuevos elementos de juicio que, con seguridad, serán objeto en los próximos meses de merecida atención por parte de los paleohispanistas.

El estudio de V-J incluye, además, una útil recopilación de las inscripciones celtibéricas ordenadas en función del soporte sobre el que están redactadas (pp. 87-101), un largo y completo apéndice sobre el sufijo -ko- (pp. 155-190) y un cuadro que resume sus posiciones sobre las declinaciones en celtibérico (pp. 191-193), así como los pertinentes índices (pp. 195-226). Junto a este valioso conjunto de aportaciones que 


\section{Francisco Beltrán}

conforma el cuerpo principal del libro (pp. 71-226), la monografía incluye también una primera parte menos satisfactoria (pp. 11-68), en la que $M^{a}$. A. Díaz y M. M ${ }^{a}$. Medrano presentan una síntesis histórica de las investigaciones arqueológicas realizadas en el yacimiento (pp. 13-34) así como unas muy discutibles observaciones sobre la etimología de Contrebia Belaisca y el papel histórico de la ciudad (pp. 34-38). ${ }^{9}$ Completan esta primera parte tres informes técnicos acerca de la placa que sirve de soporte al epígrafe (E. García), de la aleación en ella empleada (J. V. Navarro) y de la digitalización del material fotográfico (Á. Duerto), así como un apéndice gráfico relativo al yacimiento y a algunos de los materiales en él exhumados (Díaz y Medrano) (pp. 45-68).

La presente reseña se centrará en la edición y en la interpretación del epígrafe que presentan V-J, prescindiendo de entrar en la valoración de los aspectos estrictamente filológicos del estudio, que con seguridad serán objeto de atención por parte de otros colegas especializados en la materia. Los comentarios sobre la lectura del epígrafe se basan no sólo en los materiales y argumentaciones que presentan V-J en la monografía que nos ocupa, sino también en el examen directo de la placa, realizado durante el mes de diciembre de 2001 en el Museo de Zaragoza tras el tardío ingreso de la pieza en sus fondos, y en el manejo de las excelentes fotografías utilizadas por V-J para el establecimiento del texto, cuya consulta debo a la amabilidad de mi colega el prof. Jordán, de quien procede también la iniciativa de esta reseña.

\section{HALLAZGO Y DESCRIPCIÓN}

El cuarto bronce de Botorrita fue hallado en 1994 de manera accidental y sin contexto arqueológico en Jaulín, como consecuencia del traslado hasta esta localidad, próxima a Botorrita, de tierras extraídas durante las obras de ampliación de la carretera comarcal que se dirige hacia Fuendetodos a su paso por las inmediaciones del yacimiento arqueológico (p. 27). Se trata de un fragmento de placa de bronce ternario, ligeramente plomado (pp. 46-47), cuyas dimensiones máximas alcanzan $13.7 \mathrm{~cm}$ de longitud, 15.9 de anchura y c. 0.2 de grosor. El texto, bastante mal conservado, fue redactado en escritura y lengua celtibéricas, y grabado mediante incisión por ambas caras de la placa, que conservan respectivamente 10 líneas (cara A) y 8 líneas (cara B), todas incompletas, con un máximo de una veintena de signos en cada una de ellas. Tras diversos depósitos, la pieza fue ingresada a fines de 2001 en el Museo de Zaragoza, en donde se conserva.

\section{Cronología}

El hallazgo accidental de la inscripción, como ya ocurriera con Botorrita 2 y 3 , aunque por diferentes razones, nos priva nuevamente de conocer el contexto arqueológico del epígrafe que tan útil hubiera podido resultar para precisar su cronología, cuestión esta sobre la que no se

\footnotetext{
${ }^{1}$ Estás páginas reproducen el texto de Medrano y Díaz 2000, pp. 165-168.
} 
pronuncian los autores del estudio, ${ }^{2}$ por lo que tal vez no sea improcedente introducir algunos comentarios al respecto. Las ya mencionadas coincidencias textuales entre Botorrita 4 y Botorrita 1 (p. 144) así como ciertas semejanzas formales - su carácter opistógrafo y la disposición del texto invertida en una cara respecto de la otra - inducen a proponer una cronología similar para ambas inscripciones. Como es sabido, Botorrita 1 fue hallado en los niveles de destrucción de la llamada "Casa agrícola" sita en la parte baja del yacimiento, cuya destrucción se asocia al conflicto sertoriano, suceso que marca el terminus ante quem para fechar este epígrafe. ${ }^{3}$ Tal horizonte concuerda bien con la datación interna de Botorrita 2, redactado en 87 a. E., y con la fecha similar atribuida a Botorrita 3 a partir de criterios formales, ${ }^{4}$ si bien no puede descartarse una datación más temprana: en cualquier caso, debe recordarse que son muy pocas las inscripciones no monetales fechables con anterioridad al siglo I a. E. y que las reputadas como más antiguas no pueden llevarse más allá de los años 134-133 a. E., 5 por lo que el final de la segunda centuria debe considerarse, mientras no haya elementos de juicio contrarios, como el horizonte más antiguo para la epigrafía celtibérica (no monetal). En lo que respecta al horizonte final, los escasos datos disponibles siguen apuntando hacia mediados del siglo I a. E., tras la destrucción en época sertoriana de la ciudad, como el momento en el que se produjo en Contrebia Belaisca la substitución de la escritura paleohispánica y la lengua celtibérica - predominantes con claridad hasta ese momento - por el alfabeto y la lengua latinos, ${ }^{6}$ de los que el primer testimonio local, dejando de lado Botorrita 2 por ser un documento inspirado claramente por la oficina del gobernador provincial $-\mathrm{y}$ tal vez realizado materialmente en ella- ${ }^{7}$ sería el cono de alabastro tardorrepublicano (¿de época sertoriana?) con la leyenda Munic·Elaisio. ${ }^{8}$ Sin duda la utili-

\footnotetext{
${ }^{2}$ Díaz y Medrano (p. 33) datan los bronces celtibéricos contrebienses en el siglo II a. E. sin más argumentación.

${ }^{3}$ Los argumentos expuestos por Díaz y Torralba 1989-1990, p. 43 y Díaz y Medrano 1993, p. 244 para retrasar la destrucción de la casa hasta época cesariana se basan fundamentalmente en dos fragmentos de ánforas —una brindisina y la otra del tipo Lamboglia 2-, que no parecen definitivos, a juicio de M. Beltrán 1997, pp. 27-30, quien se reafirma en la datación sertoriana comúnmente admitida: las ánforas en cuestión pueden fecharse respectivamente entre la época de Sila y el año 47 a. E., y entre fines del siglo II y comienzos del I a. E., una horquilla cronológica que no parece avalar la propuesta de datación defendida por Díaz, Torralba y Medrano.

${ }^{4}$ F. Beltrán en F. Beltrán, de Hoz y Untermann 1996, pp. 38-39.

${ }^{5}$ Como recuerda de Hoz 1999, p. 456 a propósito de la lámina broncínea de Numancia (MLH IV, K.9.1), siempre naturalmente que la propuesta de Schulten 1927, pp. 47 y 165 de atribuir el campamento de Peña Redonda al asedio de Escipión sea acertada.

${ }^{6}$ F. Beltrán 1989, pp. 357-362.

${ }^{7}$ Según sugiero en F. Beltrán, de Hoz y Untermann 1996, p. 25.

${ }^{8}$ En un principio me incliné por entender el letrero como referencia a un desconocido $m u$ nic(ipium) Elaisio: F. Beltrán 1989, con los criterios de datación en pp. 364-366 y 375-376; sin embargo la comprobación del nombre personal munika en Botorrita 3 (F. Beltrán, de Hoz y Untermann 1996), obliga a considerar la posibilidad - menos conflictiva desde un punto de vista histórico - de que este rótulo recoja simplemente una fórmula onomástica personal; al respecto, F. Beltrán 1997, pp. 308-309. En tal caso carecerían de validez los argumentos
} 


\section{Francisco Beltrán}

zación de la escritura paleohispánica con posterioridad a esa fecha resulta posible, aunque es poco probable que rebasara el cambio de Era: la mayor parte de los grafitos en grafía vernácula susceptibles de ser datados con alguna precisión tiene como soporte vasos de cerámica campaniense B que, precisamente, dejan de fabricarse a mediados del siglo I a. E., ${ }^{9}$ mientras que los escasos epígrafes de fecha posterior, caso del nombre celtibérico Let[ondo], grabado sobre un vaso de terra sigillata itálica procedente de la parte oriental del yacimiento y datable a comienzos del siglo I d. E., están redactados en alfabeto latino. ${ }^{10}$ Por ello, sorprende la propuesta de datación en época flavia de los grafitos realizados sobre las columnas halladas ante el "Gran edificio de adobe" del Cabezo de las Minas, que avanzan sin argumentos Díaz y Medrano (pp. 19, 26), ${ }^{11}$ pese a que los paralelos más claros de estos soportes, correspondientes a una variante del orden toscano provincial, remiten al período tardorrepublicano, ${ }^{12}$ en el que, a mi juicio, deben seguir fechándose los grafitos de las columnas. $^{13}$

En consecuencia y con todas las cautelas expresadas, la fecha del cuarto bronce de Botorrita puede situarse en los inicios del siglo I a. E. o, en todo caso, en los años finales del II a. E.

\section{EDICIÓN DEL EPÍGRAFE}

La edición de un texto fragmentario, mal conservado y redactado además en una lengua tan parcialmente conocida como el celtibérico ofrece dificultades evidentes que, sin embargo, V-J han sabido superar con un trabajo minucioso y lleno de rigor. Su labor no descuida los aspectos paleográficos y materiales del epígrafe, escrupulosamente analizados, y recurre para la presentación del texto a las convenciones que propusimos en Botorrita $3:{ }^{14}$ recogen pues las habituales en la edición de epígrafes latinos, ${ }^{15}$ con la excepción del subrayado que se utiliza para dar cuenta de los signos dudosos. El texto se presenta en escritura paleohispánica normalizada y en transcripción latina con cada línea seguida por comentarios críticos en los que se fundamenta la lectura propuesta y se expresan, cuando el caso lo requiere, posibles alternativas, una

\footnotetext{
expuestos en F. Beltrán 1989 en favor de una rectificación de la cronología sertoriana que sugiere el contexto arqueológico.

${ }^{9}$ Una recopilación de estos grafitos en F. Beltrán, en F. Beltrán, de Hoz y Untermann 1996, pp. $19-21$ y K.1.4 ss.

${ }^{10}$ F. Beltrán 1989, p. 359 nota 10.

${ }^{11}$ Los autores remiten para justificar una cronología tan tardía a Medrano, Díaz y Tramullas 1991, pp. 281-292, en donde, sin embargo, no se trata la cuestión (véase espec. p. 285).

${ }^{12}$ A. Beltrán y M. Beltrán 1989, pp. 354 ss.; M. Beltrán 1997, p. 23, mencionando un paralelo saguntino.

${ }^{13}$ Para la edición de los grafitos, A. Beltrán 1983, p. 105. Debe tomarse además en consideración que, como señalábamos en otro lugar ( $\mathrm{F}$. Beltrán en F. Beltrán, de Hoz y Untermann 1996, p. 19), existen indicios de que los autores de estos grafitos no fueran contrebienses, pues la grafía de las letras $\mathrm{Y}, \mathrm{E}$ y $\mathrm{R}$ parecen convenir más bien al signario ibérico que al celtibérico oriental, habitual en Botorrita.

${ }^{14}$ F. Beltrán, de Hoz y Untermann 1996, pp. 43-45.

${ }^{15}$ Cf. Panciera 1991.
} 
fórmula que me sigue pareciendo idónea para la edición de los textos celtibéricos, sobre todo cuando, como en este caso, son extensos y presentan problemas de lectura. Los autores cumplen, pues, de forma pulcra y minuciosa con su tarea de editores al suministrar una sólida versión de este difícil texto, a la que, al margen de discrepancias concretas de lectura, sólo puede planteársele una objeción: la insuficiencia del aparato ilustrativo, pues las fotografías del epígrafe que presentan no permiten controlar la lectura que proponen ya sea por carecer del necesario detalle (pp. 62-63) ya sea por falta de luz en las reproducciones (pp. 81-82).

Tras haber examinado el epígrafe con detenimiento, tanto a simple vista como mediante el auxilio de binoculares, y consultado las fotografías empleadas por V-J para establecer el texto, las discrepancias de lectura respecto de la versión presentada por estos autores son mínimas: en su mayoría afectan a signos aislados y a aquéllos que V-J transcriben con dudas. Sólo en las 11. 2-4 de la cara A son las divergencias más substanciales, sobre todo por afectar a la parte del texto menos fragmentaria, en la que, lógicamente, se apoya la interpretación general del epígrafe que defienden V-J.

Cara A:

Si la lectura de la primera línea no plantea problemas

1. [---]tam tirikantam : entorkue : toutam [---],

a cambio su versión de las 11. 2-4 me parece menos segura. V-J proponen:

2. [---]sua kombal[.]z : bouitos : ozeum :+[---]

3. [---]i : turuntas : tirikantos : kustai : bize+[---]

4. [---]a : karalom : aranti $:$ otenei : ambi $++[---]$.

Mi discrepancia básica afecta a la seguridad con la que V-J leen algunos signos que, a mi juicio, no se distinguen con tanta claridad, por lo que me inclino por un texto más cauteloso:

2. $[---]+: \mathrm{s}++\mathrm{kom}+1++\underline{\underline{\mathbf{u}}}+\underline{\mathrm{itos}}:$ ozeum : $\underline{\mathrm{ku}}[---]$

3. [---]i : turuntas : tirikanto ${ }^{+}:$kustai : bize $+[---]$

4. [---]+ : karalom : arantiotenei : ambi++[---].

Línea 2. Al comienzo del renglón se aprecian restos de un trazo oblicuo que podrían corresponder al signo ka. A continuación V-J, basándose en la secuencia sua kombalkez de la primera línea de Botorrita 1, proponen leer de manera análoga una serie de signos - sin interpunción apreciable entre ellos, pero con un claro espacio ante la ko-, cuyo trazado no se distingue siempre con nitidez: tras la $s$ se conservan restos de dos signos que, como sugieren V-J, podrían corresponder en efecto a $u$ y $a$, y componer la secuencia sua, pero que sobre el bronce no consigo apreciar con claridad; a cambio, en la propuesta de V-J para la siguiente 


\section{Francisco Beltrán}

palabra, komball[.]ż , la $b a$, más que dudosa, es poco verosímil, pues además de su anómala grafía angular, parece compartir un trazo con la $m$ anterior - suponiendo que este signo, desacostumbradamente ancho, esté bien leído-, mientras que la $z$ final es, como los autores señalan, incierta. En la siguiente palabra, bouitos según V-J, el problema radica en la bo inicial, cuyo supuesto trazo transversal es muy corto, sin que haya posibilidad de corroborar esta grafía en el bronce, pues éste sería el único ejemplo de bo en el epígrafe: por ello, sin excluir que se trate de una $b o$, hay que contemplar también una posible lectura ta. Al final se aprecian dos trazos angulares con un posible punto en el medio que podrían corresponder a una $k u$.

Línea 3. En esta línea la discrepancia afecta a la propuesta tirikantos, en donde es problemático el final de la palabra, en el que tras la probable to sólo observo un trazo oblicuo descendente inidentificable. Al final, V-J, a partir del bizetuz comprobado en la 1.5 de la cara A de Botorrita 1, proponen leer bize+[---], entendiendo el último signo como una posible $t u$ - que podría, sin embargo, ser también una $r-$; sin embargo no aprecio con claridad ni la $e$ ni los restos del posible signo $t u$.

Línea 4. El signo fragmentario inicial no me parece con seguridad $a$. Respecto a la secuencia aranti: otenei, como V-J indican, no se aprecia bien la interpunción entre $t i$ y $o-$ uno de cuyos puntos ven sobre la $t i-$, mientras que el trazo interior de la te no se aprecia en toda su extensión, por lo que no puede descartarse leerla $k u$.

En el resto de la lectura las discrepancias son de menor relevancia.

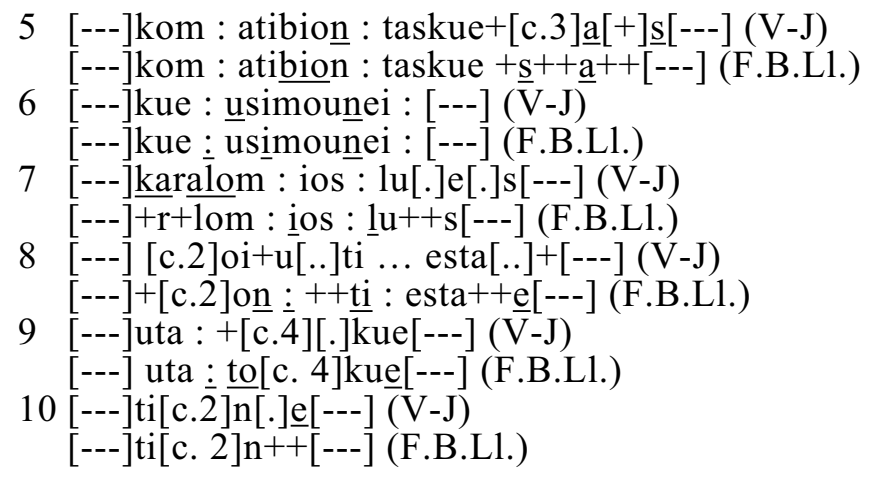

Cara B:

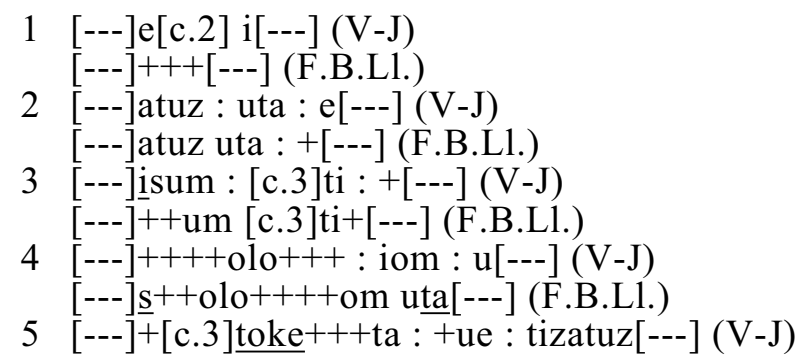




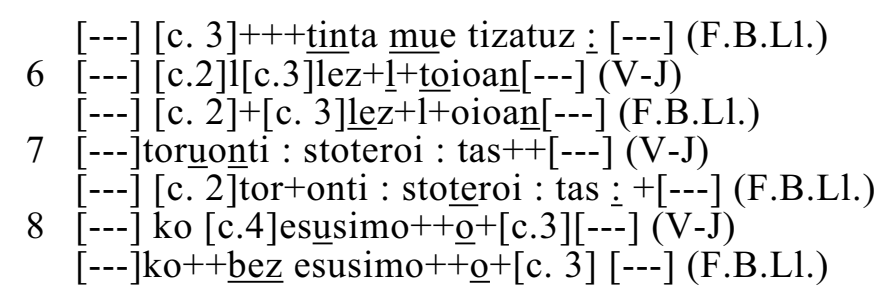

\section{INTERPRETACIÓN DEL TEXTO}

Tras un detenido análisis morfosintáctico y semántico de las palabras más completas del epígrafe (pp. 103-131), V-J abordan su interpretación (pp. 131-151) teniendo como puntos de referencia el texto celtibérico de Botorrita 1, dadas sus llamativas coincidencias con Botorrita 4, y el latino de Botorrita 2, como es sabido, alusivo a un conflicto entre tres comunidades - Salduie, Alaun y los Sosinestani-, en el que el senado de Contrebia Belaisca ejerció como árbitro.

Los claros paralelismos entre el nuevo texto y Botorrita 1 (véase el cuadro-resumen en p. 144) inducen a admitir, como defienden V-J, la naturaleza similar de ambos documentos. En un trabajo anterior Villar, tras un minucioso análisis de la línea inicial de Botorrita 1, expuso sus argumentos para descartar la difundida consideración de este epígrafe como un texto religioso por entender que en ese primer renglón de la inscripción lo que se planteaba era un conflicto de índole territorial, inclinándose en consecuencia por entender los términos tokoitos y sarnikio, en cuya relevancia coinciden todos los estudiosos del epígrafe, como topónimos en lugar de teónimos. ${ }^{16}$ En la monografía que nos ocupa V-J profundizan en esta línea de razonamiento exponiendo serias objeciones contra el principal argumento en el que se basa la caracterización de estas palabras como teónimos y, en consecuencia, la interpretación del epígrafe como una especie de lex sacra: a saber, la identificación de tokoitos con las divinidades Togoti y Togia atestiguadas en epígrafes latinos de Hispania, que coincido con V-J en considerar poco fundamentada. ${ }^{17}$ Descartada esta opción, cobra fuerza la hipótesis de que los mencionados términos, interpretados casi unánimemente como nombres propios, sean topónimos. A este respecto V-J proponen identificar tokoitos con la ilocalizada ciudad ibérica que emitió moneda en el valle medio del Ebro con la leyenda Iltukoite: ${ }^{18}$ tanto lingüística como históricamente la propuesta resulta verosímil - aunque no pueda darse por probada-y, de hecho, Botorrita 2 y Botorrita 3 ponen de manifiesto con claridad que la presencia de nombres de persona o de comunidades políticas no celtibéricas en un epígrafe contrebiense resulta perfectamente esperable, sobre todo si tales comunidades eran vecinas de Contrebia, como bien podría ser el caso de Iltukoite. A cambio, en lo que respecta a sarnikio, V-J sugieren su aproximación a la ciudad de Sarna, mencionada por

\footnotetext{
${ }^{16}$ Villar 1990.

${ }^{17}$ En este mismo sentido me manifiesto en F. Beltrán en prensa.

${ }^{18}$ MLH I, A.20.
} 


\section{Francisco Beltrán}

Avieno en la Ora maritima (v. 497), que resulta aceptable como paralelo, aunque, como V-J reconocen, difícilmente pueda admitirse su identidad con el término del epígrafe contrebiense, pues, dejando al margen otras consideraciones, la Sarna de Avieno - conocida sólo a través de este testimonio- debía de ser una población costera y, por lo tanto, excesivamente alejada del ámbito de relación de Contrebia Belaisca como para ser tomada en consideración. Más problemática es, por último, la suposición de que en el asunto que se substancia en Botorrita 1 estuvieran implicados también los habitantes de una tercera ciudad, a los que haría referencia el término akainakubos en la 1.9 de la cara A. Pues, a diferencia de tokoitos y sarnikio - mencionados reiteradamente en el texto-, esta presunta tercera ciudad sólo aparece una vez en dicha cara $\mathrm{y}$, además, denominada no por su topónimo, sino mediante un adjetivo que habría que entender como un gentilicio referente a sus pobladores. Por otro lado, akainaz figura también en la cara B - en donde no se mencionan tokoitos ni sarnikio -, articulando, al parecer, una lista de personas junto con los términos lubinaz, nouantutas ${ }^{19}$ y [.. $]$ ukontaz, que, en consecuencia, deberían ser forzosamente entidades semejantes a akaina, y en tal caso no serían tres, sino seis las comunidades afectadas por la disposición que contiene Botorrita 1 ... Aunque la interpretación de estos cuatro términos como topónimos sea verosímil, ${ }^{20}$ ello no implica, sin embargo, que deban ser necesariamente poleónimos - de hecho, no se han señalado paralelos satisfactorios en esta dirección- y no topónimos menores o, como opinan algunos estudiosos, designaciones de las subdivisiones internas del cuerpo cívico contrebiense, ${ }^{2 \mathrm{P}}$ por lo que creo preferible desligar su tratamiento del de tokoitos y sarnikio.

En lo que respecta a Botorrita 4, son dos los presuntos topónimos que V-J detectan en el texto. Uno es karalom, término atestiguado con seguridad en la 1. 4 de la cara A y tal vez también en la 1.7 de esa misma cara, $+r+$ lom $-\mathrm{o}$ karalom, según V-J-, que identifican con la karaluz monetal $^{22}$ y que bien pudiera corresponder efectivamente al gentilicio Gralliensis mencionado por un epígrafe de $\operatorname{Tarraco}^{23}$ y tal vez por Plinio el Viejo en su nómina de comunidades del convento jurídico cesaraugustano. ${ }^{24}$ El otro sería aranti, en la cuarta línea de la cara A, que V-J identifican con la comunidad que emitió moneda con las leyendas aratiz y $\operatorname{aratikos}^{25}$ y que cuenta con el paralelo de Arandis en Lusitania, ${ }^{26}$ pero

\footnotetext{
${ }^{19}$ Esta lectura me sigue pareciendo preferible a nouantubos, defendida por Untermann MLH IV, K.1.1.

${ }^{20}$ Como propuso en primer lugar Tovar en A. Beltrán y Tovar 1982, p. 78, considerándolos vagamente como 'entidades de población'.

${ }^{21}$ En este último sentido de Hoz 1986, p. 82; Marco 1999.

${ }^{22}$ MLH I, A. 63.

${ }^{23}$ CIL II 4244, datable a comienzos del siglo II d. E.

${ }^{24}$ Plin. NH III 24; F. Beltrán 2000, pp. 78-79: la lectura enmendada de Jan, $<I>$ spallenses, aceptada en la edición de Mayhoff 1906, no parece preferible a la variante grallenses atestiguada en la segunda mano del códice Florentino Ricardiano realizada, según Mayhoff 1906, p. IX a partir de "codicis ex ordine uetustiorum".

${ }^{25}$ MLH I, A. 65.

${ }^{26}$ It. Ant. 426.2 .
} 
que plantea el problema, admitido por $\mathrm{V}-\mathrm{J}$, de aparecer en una secuencia de difícil segmentación: arantiotenei $-\mathrm{o}$ aranti $:$ otenei, según $\mathrm{V}-\mathrm{J}-$ (pp. 126-129).

Respecto del contenido específico del texto, V-J se inclinan por considerar que en él ¿el senado contrebiense? (kombal[.Jz) establecería las normas de utilización de un territorio (tirikantam) - con una población en su interior (entorkue toutam) - , vinculado con el paso de ganado vacuno o con un camino (bouitos), cuya anchura podría indicarse a continuación, si ozeum $\mathrm{ku} /---/---] i$ puede entenderse, tal y como proponen, como una referencia a la misma estimada en cuatro ( $\mathrm{ku}[\mathrm{e}$ etuor]i o $\underline{k u[e t o r] i}$ ?) pies (ozeum), en paralelo al ozas sues de Botorrita 1. Más concretamente proponen la siguiente traducción para las 1l. 1-3 de la cara A: "Respecto al 'territorio' de Turunda y al pueblo que hay en su interior así decidió [¿el senado?]" (...) "el camino sea de 4 pies a la entrada del tres cantos de Turunta" y a continuación una referencia al kustai, tal vez el "vigilante o custodio de la entrada". En la 1. 4 serían introducidas en el texto las dos ciudades que, según V-J, protagonizan el conflicto dirimido por el senado contrebiense: karalom y aranti.

Esta sugerente compresión del texto reposa en una serie de coherentes razonamientos sobre el contenido semántico de los términos en cuestión y en una brillante explotación de los paralelismos entre este texto y Botorrita 1, particularmente en las líneas 1 -en donde se menciona también la palabra tirikantam - y 4-5. En el estado actual de nuestros conocimientos sobre el celtibérico, este ensayo de traducción reune todos los requisitos necesarios para ser tomado en consideración con toda seriedad, aunque sin ocultar las dudas que pesan sobre la traducción de los términos o, incluso, sobre su correcta lectura. Así en lo que respecta a tirikantam, ${ }^{27}$ V-J se inclinan por traducirlo como "territorio" o "tres cantos", entendiendo que ese espacio estaría de alguna manera definido por tres límites, como parece sugerir el primer segmento numeral del término, si bien valoran también la posibilidad de que pudiera significar "litigio" o algo similar: de hecho y dada la hipótesis que defienden -es decir que Botorrita 1 y 4 fueran arbitrajes similares a Botorrita 2-, este último significado, "arbitraje", una operación que exige la actuación de tres partes, encajaría perfectamente con su interpretación de los textos. Respecto de bouitos ya hemos señalado las dudas de lectura que afectan al primer signo, por lo que su comprensión como "camino de vacas" o algo similar queda en suspenso (pp. 108-109). Y lo mismo cabría decir de $k o \underline{m}+l++(1.2)$, cuya aproximación al kombalkez de Botorrita 1, me parece arriesgada, lo mismo que la de $\underline{\text { bize }} \underline{+}^{+}$al bizetuz de ese mismo epígrafe. Por último, recuérdese que la segmentación de la secuencia arantiotenei (1. 4) tampoco es segura.

Con todo, la explicación del texto formulada por V-J sitúa la discusión sobre los bronces contrebienses en una nueva perspectiva y no sólo por la materia sobre la que Botorrita 1 y 4 versarían, sino sobre todo por

\footnotetext{
${ }^{27}$ Las reflexiones de V-J sobre la morfología de este término (pp. 104-107), apoyadas en la lectura tirikantos de la 1. 3, se enfrentan al problema de la dudosa identificación del último signo de esta palabra que, según lo expuesto más arriba, prefiero leer tirikanto + .
} 
la consideración de que ambos textos sean, como se ha dicho, arbitrajes similares a Botorrita 2. Esta conclusión induce a V-J a plantear como corolario histórico la hipótesis de que la acumulación de textos broncíneos en Contrebia Belaisca obedeciera a su condición de centro de una especie de distrito jurídico, cuyos integrantes someterían al senado contrebiense sus litigios (pp. 151-153).

Para explicar tal función recurren a la etimología del poleónimo, *kom-*treb $(h)$, que, a su juicio, podría referirse no tanto a una "reunión de casas", alusiva al proceso de sinecismo o formación de la ciudad, ${ }^{28}$ cuanto a un "conjunto de ciudades que se agrupan con fines que en nuestro caso serían jurídicos" (p. 152), en paralelo al significado latino de conuentus (iuridicus). En tal caso, Contrebia asociado al epíteto Belaisca significaría algo parecido a "Conuentus Bellorum". No obstante los mismos V-J señalan una seria objeción para tal interpretación: a saber, que no sea bela, ni siquiera celtibérica, ninguna de las dos ciudades - Alaun y Salduie-que encomienda el arbitraje de sus diferencias al senado contrebiense en Botorrita 1, circunstancia que en efecto no abona la comprensión del poleónimo como "Conuentus Bellorum" o "Reunión de los Belos". Pero, además, se plantean otros problemas de índole histórica. La información numismática, literaria y epigráfica disponible pone de manifiesto la autonomía de las ciudades celtibéricas así como la escasa relevancia política de las etnias: ${ }^{29}$ con esta imagen encaja mal la existencia de circunscripciones jurídicas como las sugeridas por V-J, en las que, por un lado, una ciudad no sólo tendría competencias para juzgar los asuntos de otras, limitando así su autonomía, sino que habría sido fundada o rebautizada para ejercer dicha función en el marco de una etnia - que es lo que en última instancia supone explicar el poleónimo Contrebia Belaisca como "conuentus Bellorum"-, un marco que, además, desbordaría extendiendo dichas competencias sobre ciudades de lengua y adscripción étnica diferentes - vascona, ibérica y celtibérica-. Por otro lado, la aproximación de este supuesto distrito judicial a los conuentus iuridici creados por Augusto no resulta del todo satisfactoria, pues éstos consistían en meras reuniones de comunidades provinciales en un lugar y fecha dados que convocaba el gobernador para facilitar su labor judicial. En ningún caso tales funciones eran asumidas por la capital conventual que actuaba como mera sede de justicia del magistrado que regía la provincia, por lo que difícilmente los conventos jurídicos de fecha imperial o sus precedentes republicanos - cuya existencia es inseparable del funcionamiento de la administración romana- pueden apoyar la hipotética existencia de circunscripciones como la que proponen $\mathrm{V}-\mathrm{J}$, en la que sería una ciudad la que dispusiera de jurisdicción sobre otras comunidades.

La explicación del conflito que queda plasmado en Botorrita 2 no requiere de la existencia de un distrito jurídico celtibérico como el que proponen V-J. En este caso, son dos ciudades no sólo próximas, sino

\footnotetext{
${ }^{28}$ Según sugirió Lejeune 1955, p. 68 nota 170 y han aceptado otros investigadores como, p. ej., Marco 1999.

${ }^{29}$ F. Beltrán 1992, pp. 195 ss.; Burillo 1998.
} 
seguramente colindantes con Contrebia Belaisca, pero pertenecientes a grupos étnicos diferentes - vascona la una e ibérica la otra-, las que, bajo la atenta supervisión del gobernador romano, someten sus diferencias al arbitraje de su vecina celtibérica. Probablemente, la diferente adscripción étnica de Contrebia podía resultar a los ojos de los litigantes una garantía de neutralidad, mientras que su proximidad geográfica y su presunta familiaridad con los asuntos de las dos comunidades vecinas la situaba en condiciones idóneas para emitir un arbitraje con conocimiento de causa. Cuestión diferente es que la redacción del veredicto en latín y empleando planteamientos jurídicos propios del derecho romano así como su exhibición pública, grabado sobre una plancha de bronce, en la ciudad que había ejercido de árbitro en el litigio pudiera obedecer a su condición de sede del tribunal del gobernador provincial, en una prefiguración de los conventos jurídicos de época augústea, según he sugerido en otro lugar. ${ }^{30}$ Por todo lo expuesto, no termina de convencerme la hipótesis de que el nombre de Contrebia Belaisca encierre una referencia a un distrito judicial (o kontrebia) interétnico y de que en éste radique la explicación de la acumulación de textos broncíneos en Botorrita.

Todo ello no excluye, desde luego, la posibilidad de que Contrebia Belaisca pudiera haber ejercido entre sus vecinos el papel de árbitro y que de la misma forma que resolvió el litigio entre Salduie y Alaun, pudiera haber sido reclamada su intervención en otros conflictos de ciudades próximas como los que, si se confirma la interpretación de V-J, enfrentaron a Iltukoite y Sarnikios (Botorrita 1) o a karalom y aranti (Botorrita 4). Pero en tal caso no sería la existencia de un distrito jurídico indígena, sino el prestigio de la ciudad y su senado, y su condición de sede - aunque fuera temporal - del tribunal del gobernador provincial $\mathrm{y}$, en consecuencia, lugar de reunión de las comunidades de la región, las que motivarían su elección como árbitro. Por otra parte, conviene subrayar que Botorrita 2, el único documento en el que con seguridad Contrebia desempeña el papel de árbitro entre ciudades vecinas, se detectan algunas particularidades respecto de Botorrita 1 y 4: por un lado, la ciudad que ejerce de árbitro, Contrebia, es mencionada repetidamente en Botorrita 2 -que, de hecho, comienza con las palabras Senatus Contrebiensis-, mientras que ni Botorrita 1 ni la parte conservada de Botorrita 4 recogen el nombre de la ciudad; por otro lado, la enumeración de magistrados que encierra Botorrita 2 puede encontrar un paralelo en la lista de personajes que aparecen en la cara B de Botorrita 1, sin embargo no parece que tal circunstancia se dé en Botorrita 4, por más que el carácter fragmentario del texto impida pronunciarse al respecto con rotundidad.

Sirvan esta reflexiones ante todo para poner de relieve el interés que a mi juicio encierra la sugerente interpretación planteada por Francisco Villar y Carlos Jordán, que, con seguridad, seguirá alimentando en lo sucesivo el debate sobre los bronces contrebienses.

${ }^{30}$ F. Beltrán en F. Beltrán, de Hoz y Untermann 1996, pp. 23 ss. 


\section{BIBLIOGRAFÍA}

Beltrán, A. y Tovar = A. Beltrán y A. Tovar, Contrebia Belaisca (Botorrita, Zaragoza). I. El bronce con alfabeto 'ibérico' de Botorrita, Zaragoza 1982.

Beltrán, A. 1983 = A. Beltrán, "Epigrafía ibérica de Contrebia Belaisca (Botorrita, Zaragoza): inscripciones menores", en Homenaje al prof. Martín Almagro Basch. III, Madrid 1983, pp. 99-107.

Beltrán, A. y Beltrán, M. 1989 = A. Beltrán y M. Beltrán, "Hipótesis sobre la función del gran edificio de adobe de Contrebia Belaisca (Botorrita, Zaragoza)", XIX Congreso Arqueológico Nacional, II, Zaragoza 1989, pp. 353-359.

Beltrán, F. 1989 = F. Beltrán, "Munic. Elaisio: sobre un nuevo municipio atestiguado en Botorrita (Zaragoza)", en Epigrafía jurídica romana, Pamplona 1989, pp. 357-376.

Beltrán, F. 1992 = F. Beltrán, "Parentesco y ciudad en la Céltica hispana", Dialogues d'histoire ancienne 18, 1992, pp. 189-220.

Beltrán, F. 1997 = F. Beltrán, "Epigrafía romana", Crónica del Aragón antiguo de la Prehistoria a la Alta Edad Media (1987-1993). Caesaraugusta 72, 1997, pp. 275-333.

Beltrán, F. 2000 = F. Beltrán, "El terminus republicano de Fuentes de

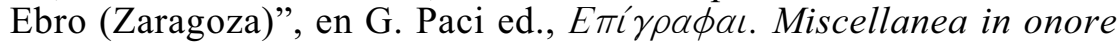
di Lidio Gasperini, Tivoli 2000, pp. 71-82.

Beltrán, F. en prensa $=$ F. Beltrán, "Les dieux des Celtibères orientaux et les inscriptions: quelques remarques critiques", en Dieux des celtes (Luxembourg 2001), Luxembourg en prensa.

Beltrán, F., de Hoz y Untermann 1996 = F. Beltrán, J. de Hoz y J. Untermann, El tercer bronce de Botorrita (Contrebia Belaisca), Zaragoza 1996.

Beltrán, M. 1997 = M. Beltrán, "Roma. República", Crónica del Aragón antiguo de la Prehistoria a la Alta Edad Media (1987-1993). Caesaraugusta 72, 1997, pp. 11-94.

Burillo 1998 = F. Burillo, Los celtíberos. Etnias y estados, Barcelona 1998. $C L C P=$ Coloquios sobre lenguas y culturas paleohispánicas.

de Hoz 1986 = J. de Hoz, "La epigrafía celtibérica" en G. Fatás ed., Epigrafía hispánica de época romano-republicana, Zaragoza 1986, pp. 43-102.

de Hoz 1999 = J. de Hoz, "Los metales inscritos en el mundo griego y periférico y los documentos celtibéricos en bronce", en F. Villar y F. Beltrán eds., Pueblos, lenguas y escrituras en la Hispania prerromana (VII CLCP), Salamanca 1999, pp. 433-470.

Díaz y Torralba 1989-1990 = M. A. Díaz y J. Torralba, "Las ánforas de Contrebia Belaisca: precisiones cronológicas", Caesaraugusta 6667, 1989-1990, pp. 29-55.

Díaz y Medrano 1993 = M. A. Díaz y M. M. Medrano, "Primer avance sobre el gran bronce celtibérico de Contrebia Belaisca (Botorrita, Zaragoza)", AEspA 67, 1993, pp. 243-258.

Fatás $1980=$ G. Fatás, Contrebia Belaisca (Botorrita, Zaragoza). II. Tabula Contrebiensis, Zaragoza 1980. 
Lejeune $1955=$ M. Lejeune, Celtiberica, Salamanca 1955.

Marco 1999 = F. Marco, "El bronce de Botorrita (cara B) como expresión de sinecismo politano" en F. Villar y F. Beltrán eds., Pueblos, lenguas y escrituras en la Hispania prerromana (VII CLCP), Salamanca 1999, pp. 269-280.

Mayhoff $1906=$ K. Mayhoff, C. Plini Secundi naturalis historiae, Stuttgart 1985 (reedición).

Medrano y Díaz 2000 = M. Medrano y M. A. Díaz, "Novedades acerca de las ciudades celtas de Contrebia Belaisca y Nertobriga", Salduie 1, 2000, pp. 165-179.

Medrano, Díaz y Tramullas $1991=$ M. M. Medrano, M. A. Díaz y J. Tramullas, "Reconstitución del edificio monumental de Contrebia Belaisca (Botorrita, Zaragoza)", Complutum 1, 1991, pp. 281-292.

MLH I = J. Untermann, Monumenta linguarum Hispanicarum.. I. Die Münzlegenden, Wiesbaden 1975.

MLH IV = J. Untermann, Monumenta linguarum Hispanicarum. IV. Die tartessischen, lusitanischen und keltiberischen Inschriften, Wiesbaden 1997.

Panciera 1991 = S. Panciera, "Struttura dei supplementi e segni diacritici dieci anni dopo", Supplementa Italica 8, Roma 1991, pp. 9-21.

Schulten 1927 = A. Schulten, Numantia. II. Die Lager des Scipio, München 1927.

Villar 1990 = F. Villar, "La línea inicial del bronce de Botorrita", Studia Indogermanica et Palaeohispanica in honorem A. Tovar et L. Michelena, Vitoria / Gasteiz 1990, pp. 375-392.

Francisco Beltrán Lloris

Universidad de Zaragoza e-mail:fbeltran@posta.unizar.es 
Francisco Beltrán
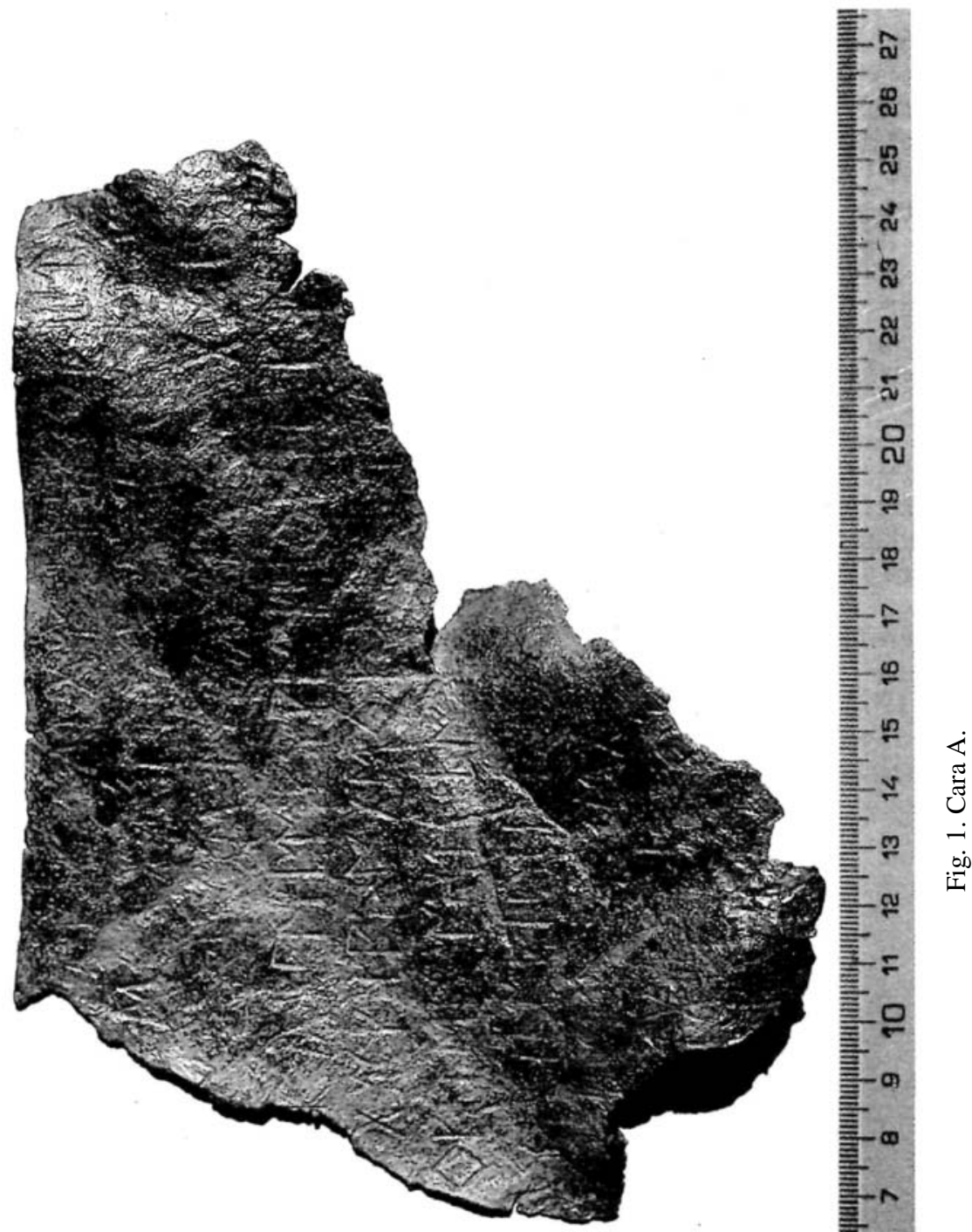
El cuarto bronce de Botorrita

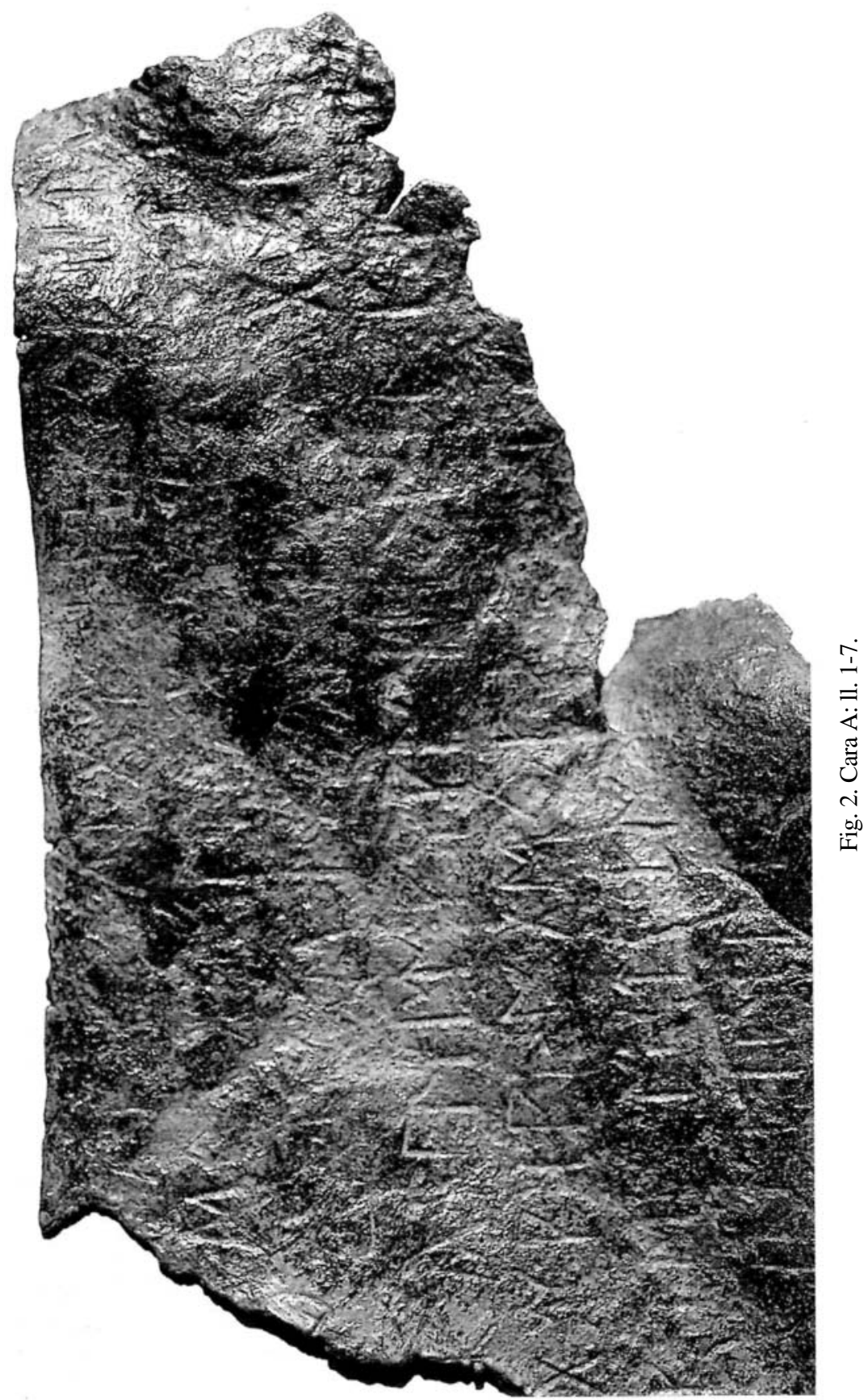

PalHisp 2 
Francisco Beltrán

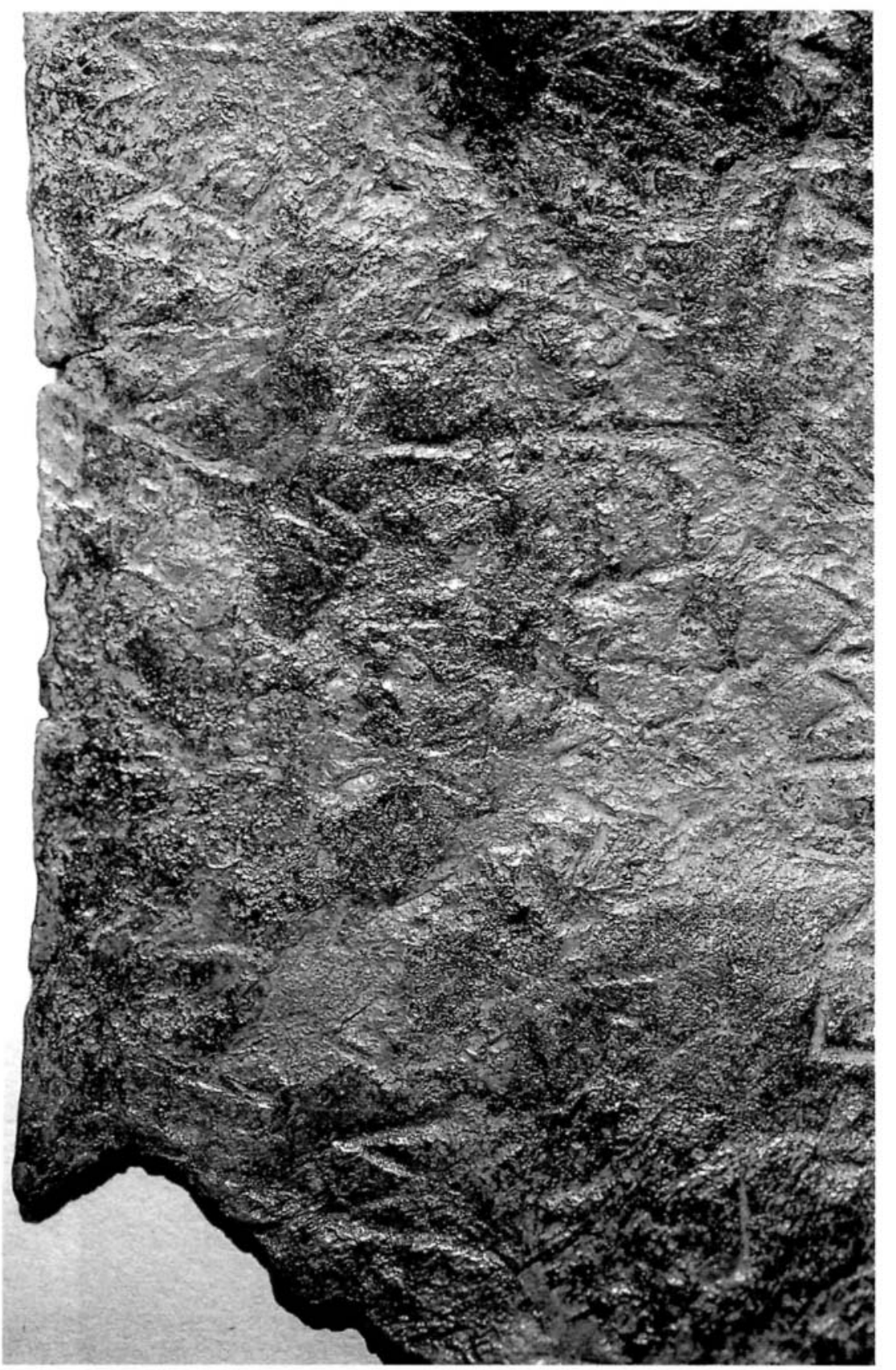

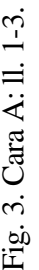


El cuarto bronce de Botorrita

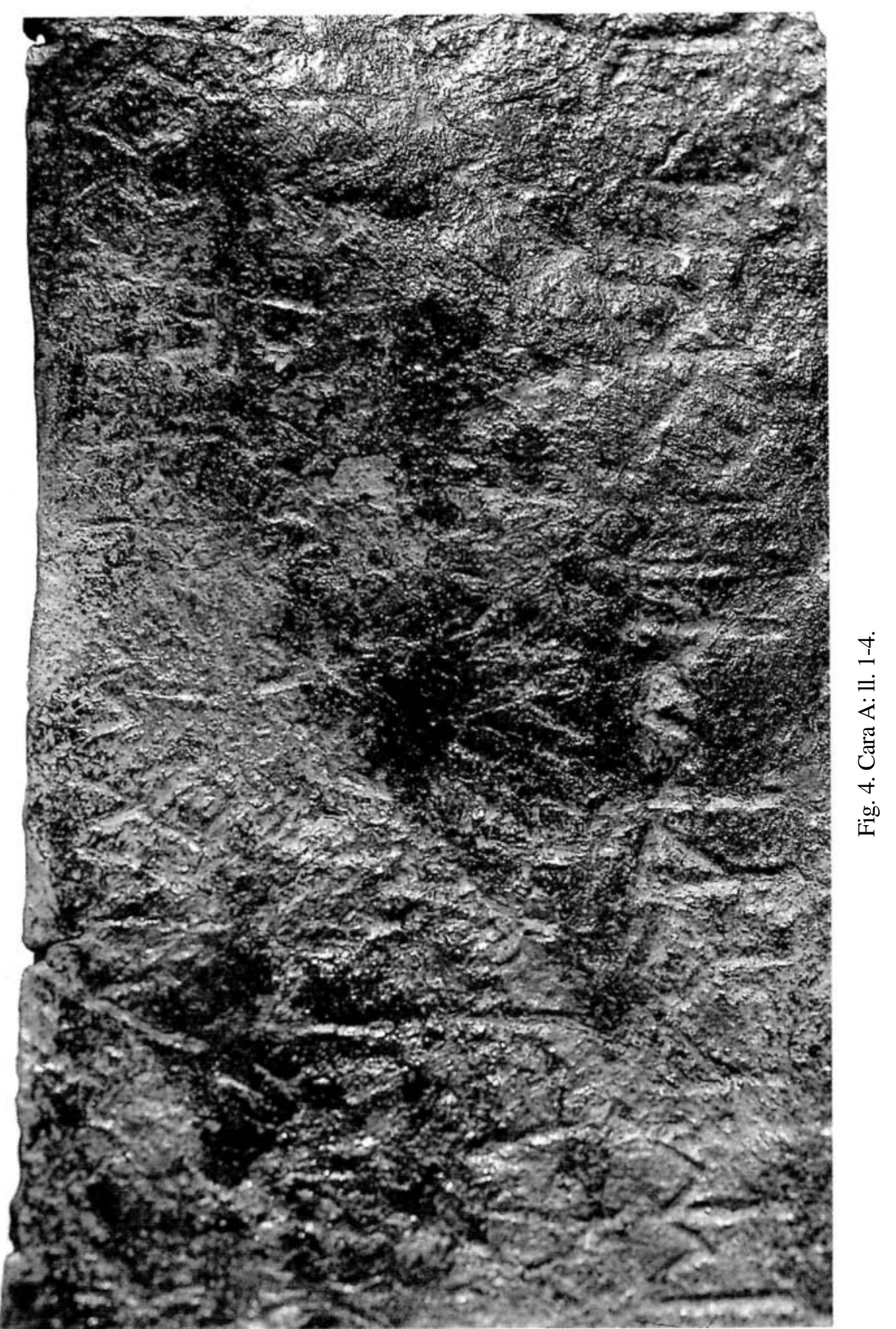




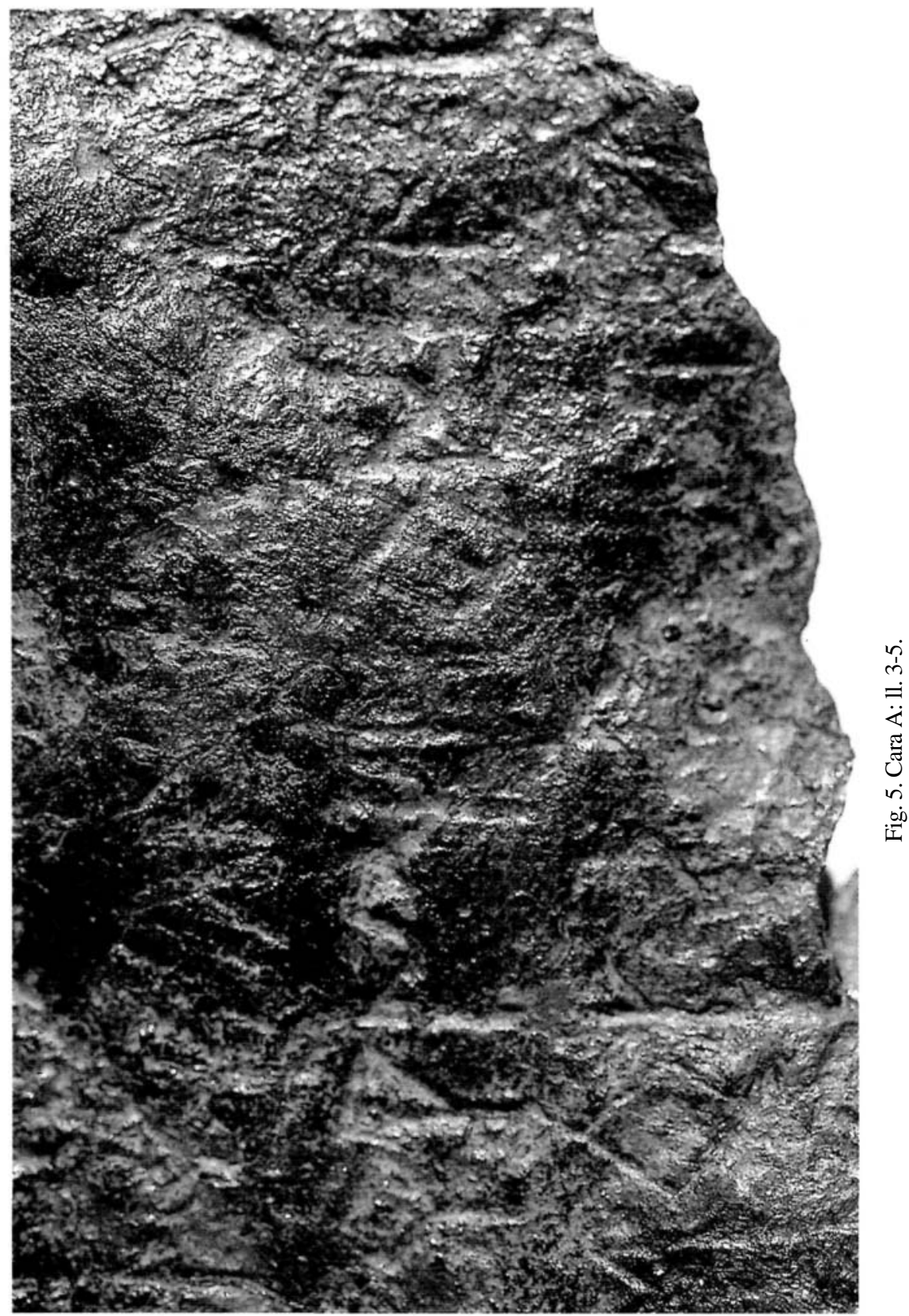


El cuarto bronce de Botorrita

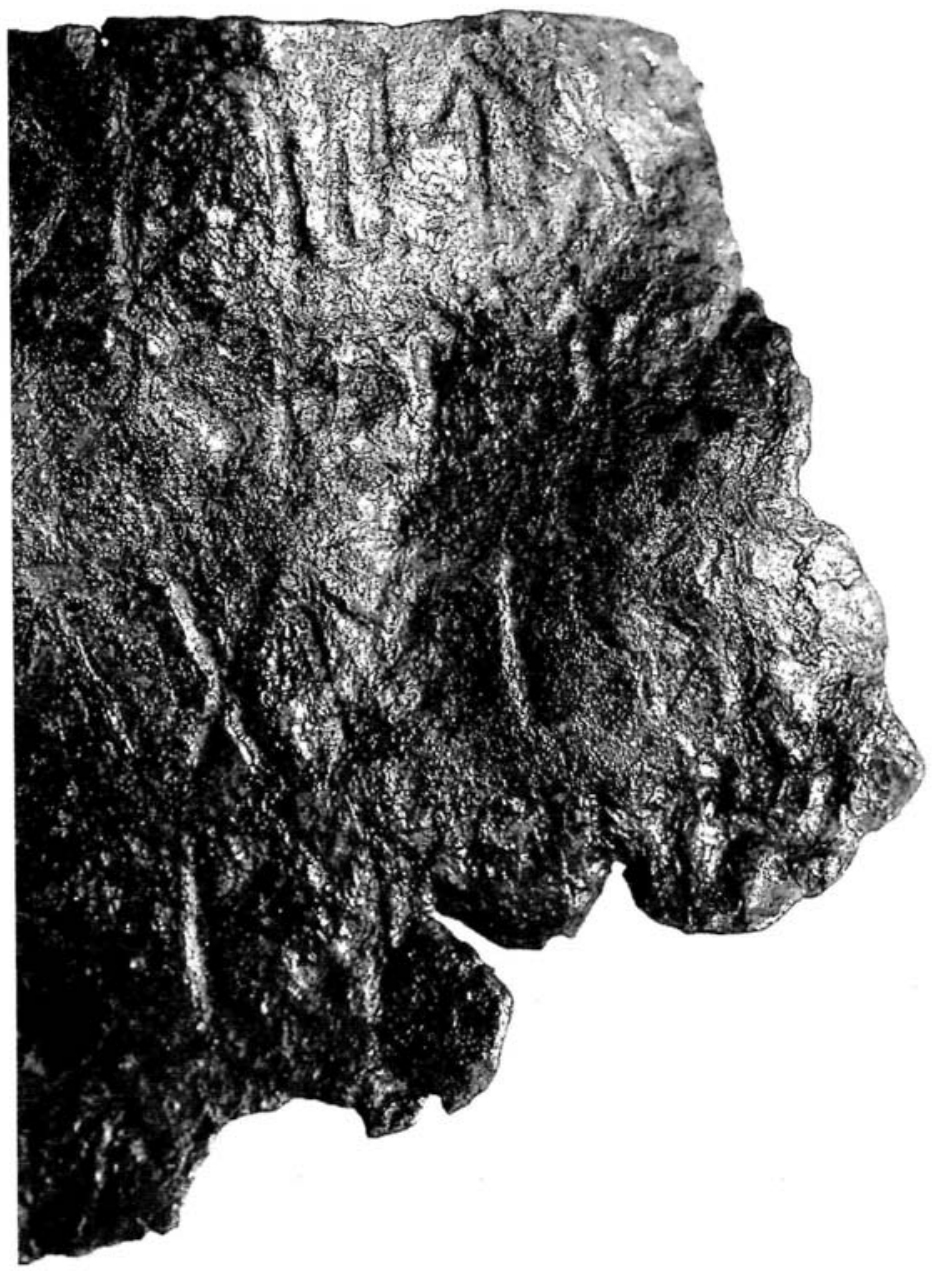

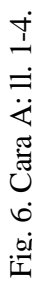


Francisco Beltrán

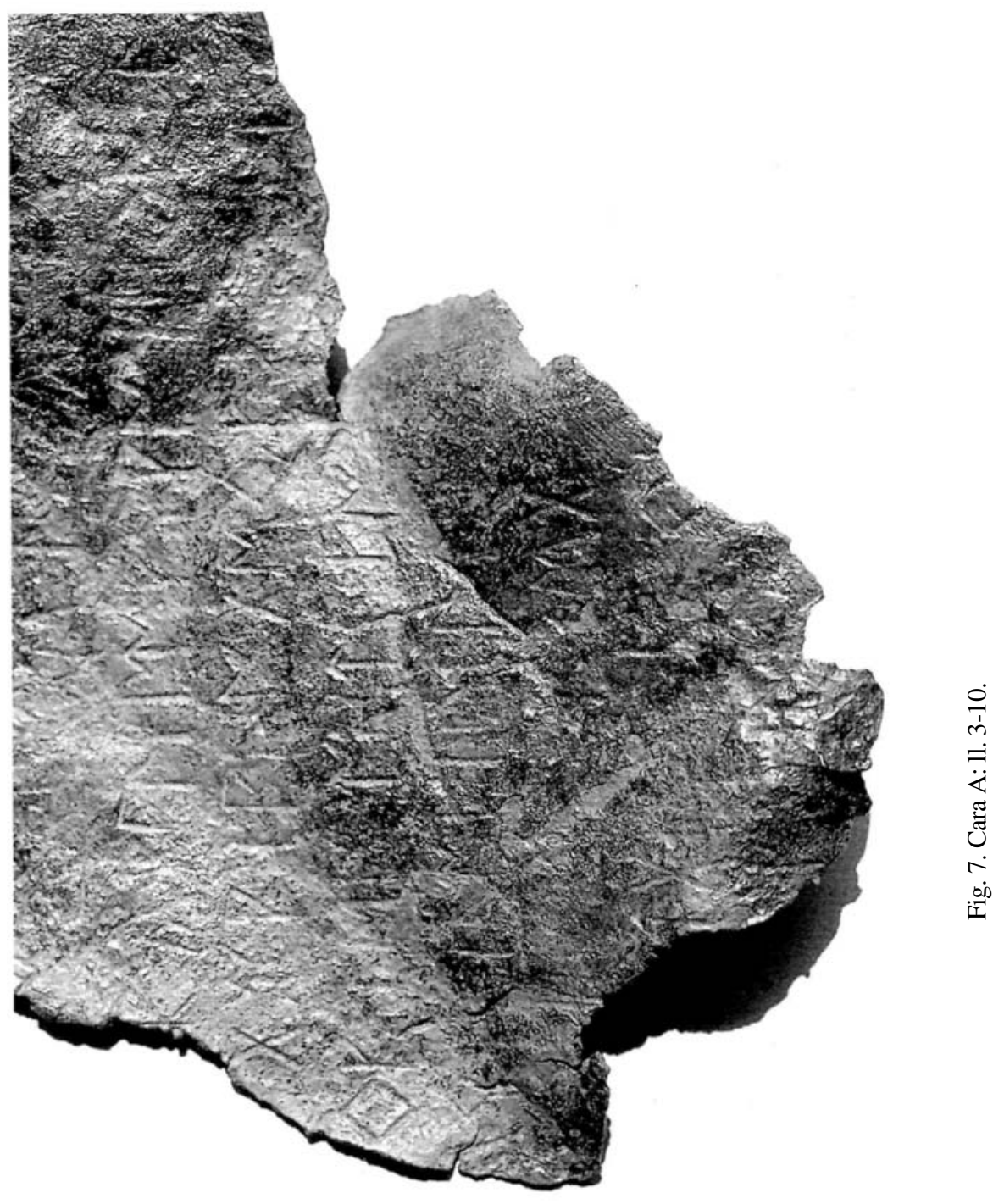




\section{El cuarto bronce de Botorrita}

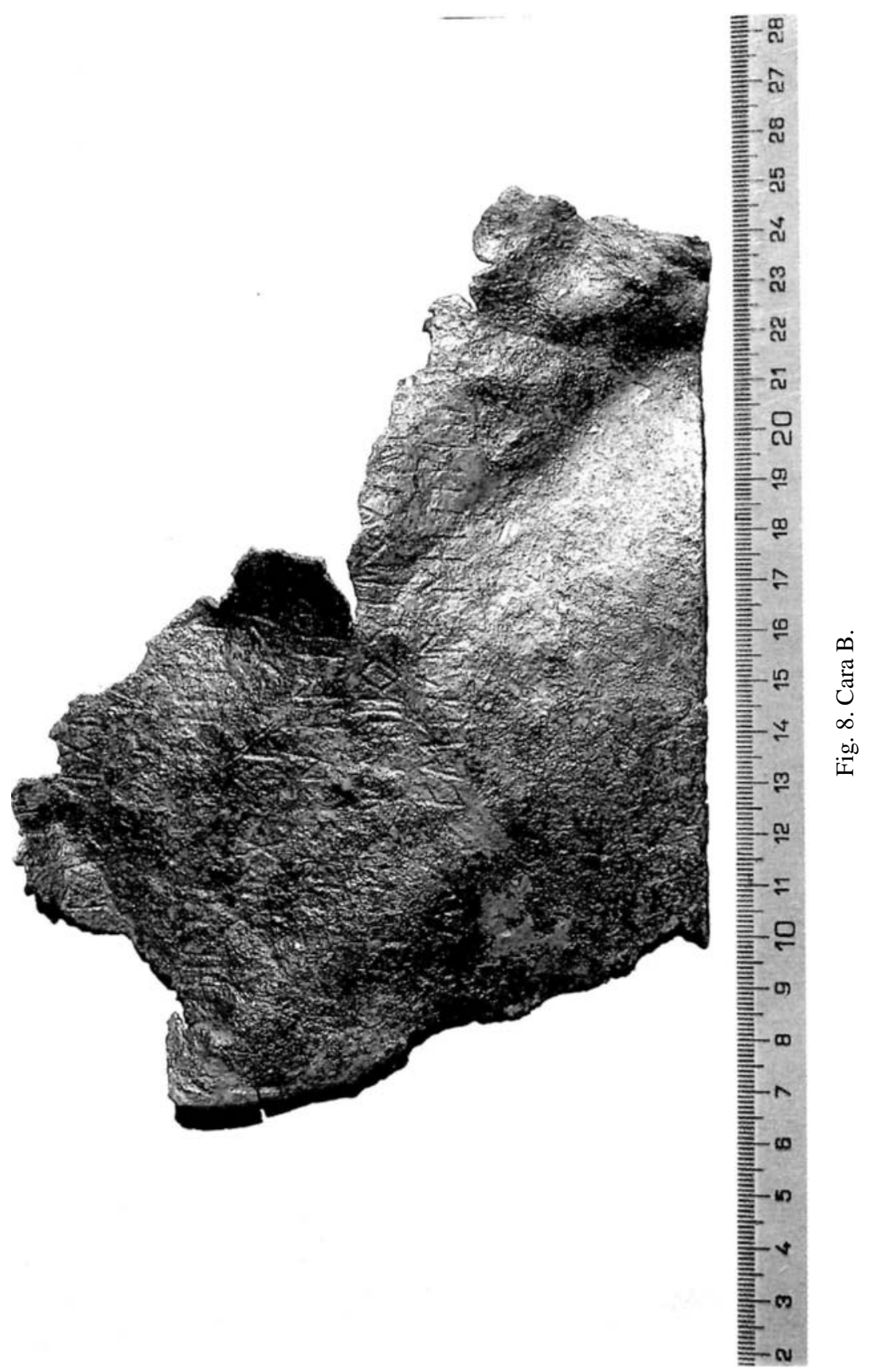




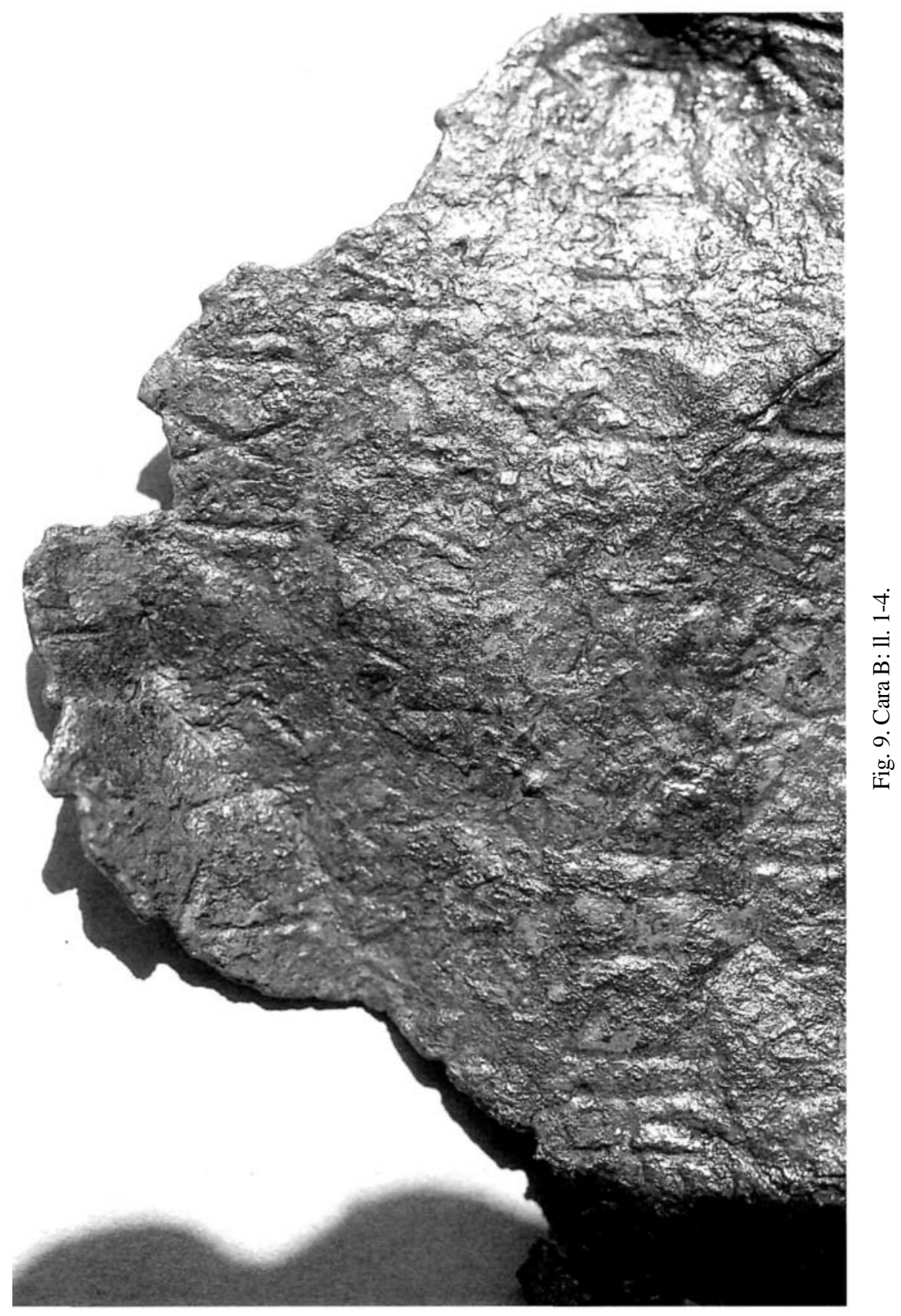


El cuarto bronce de Botorrita

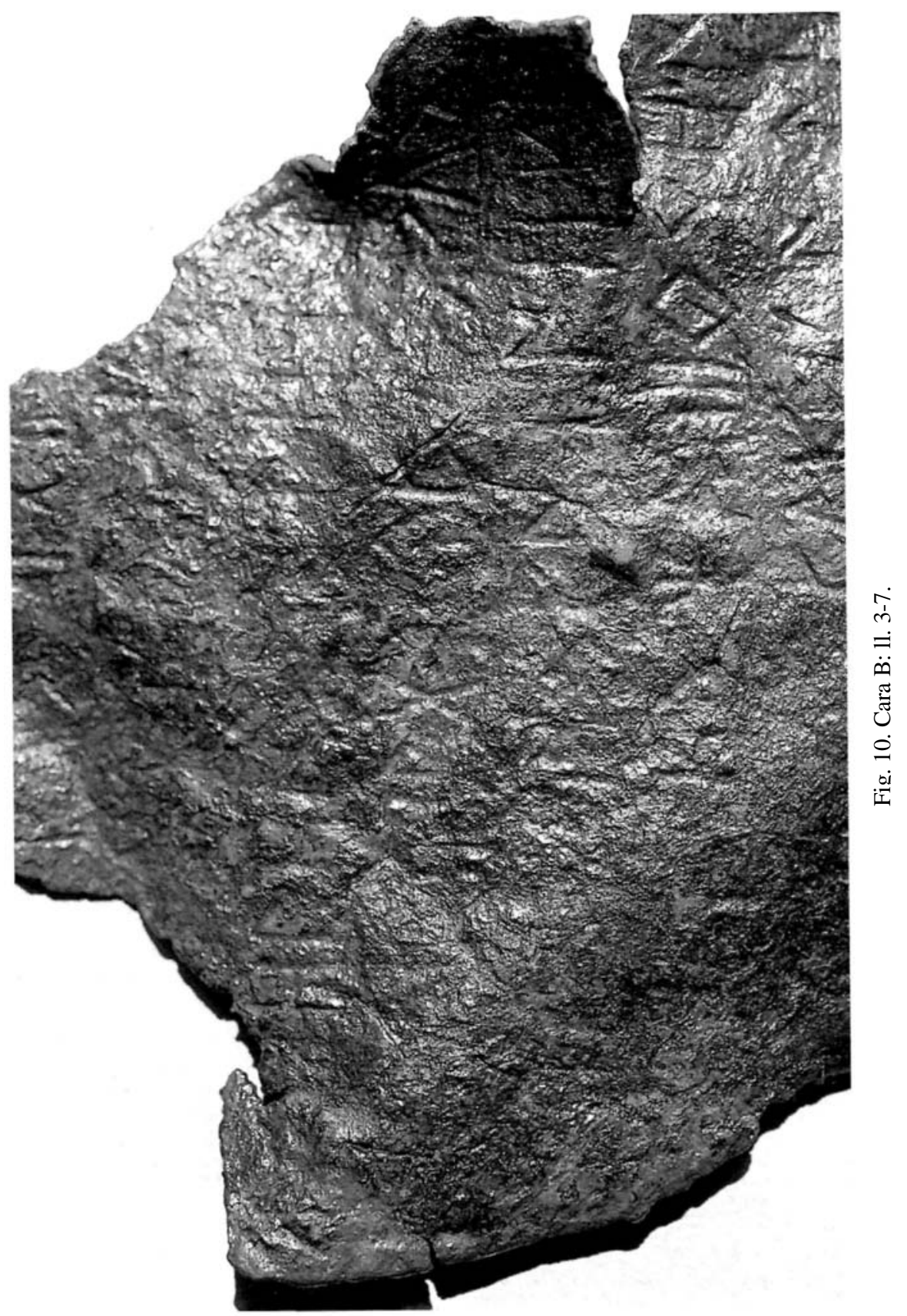




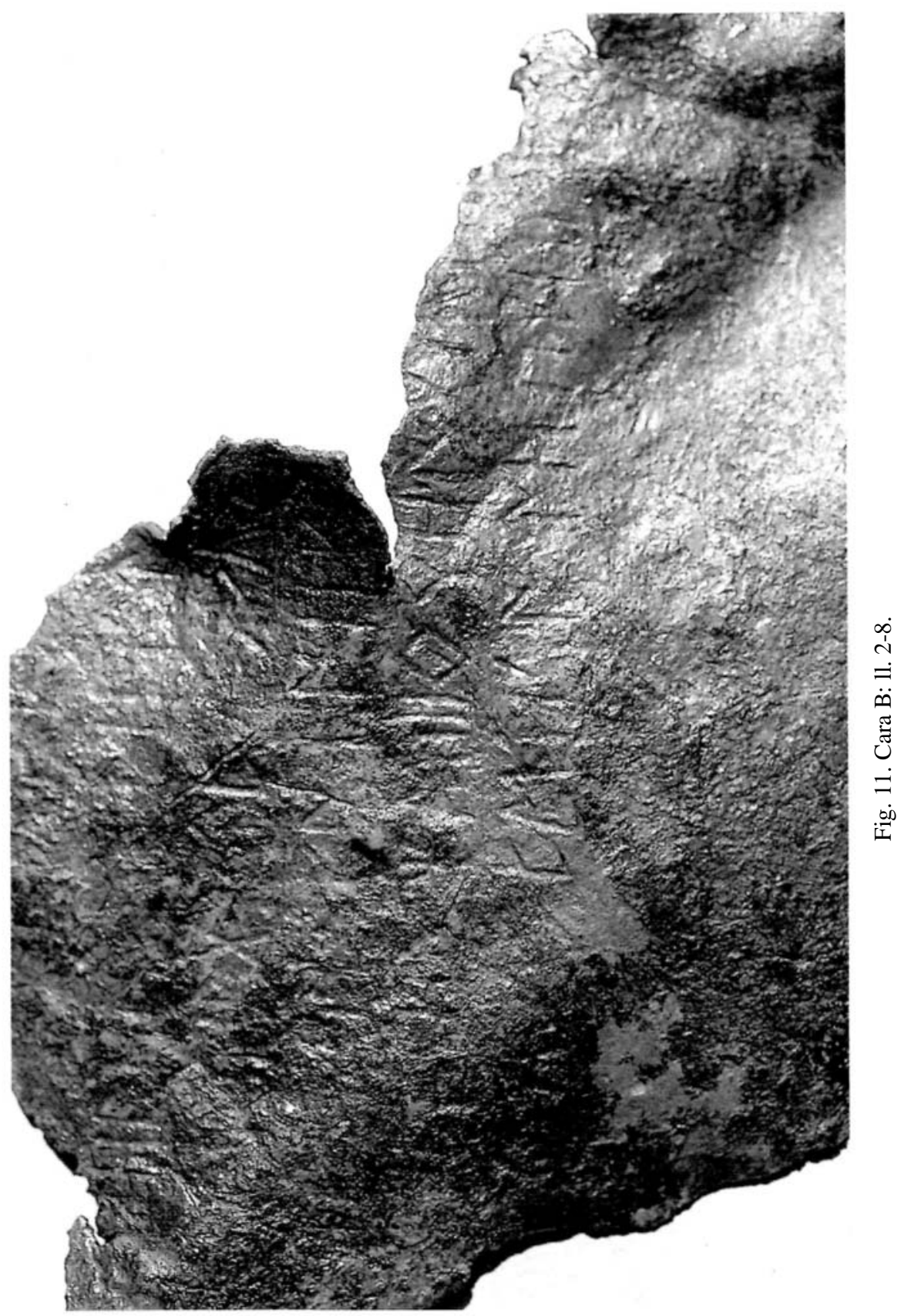




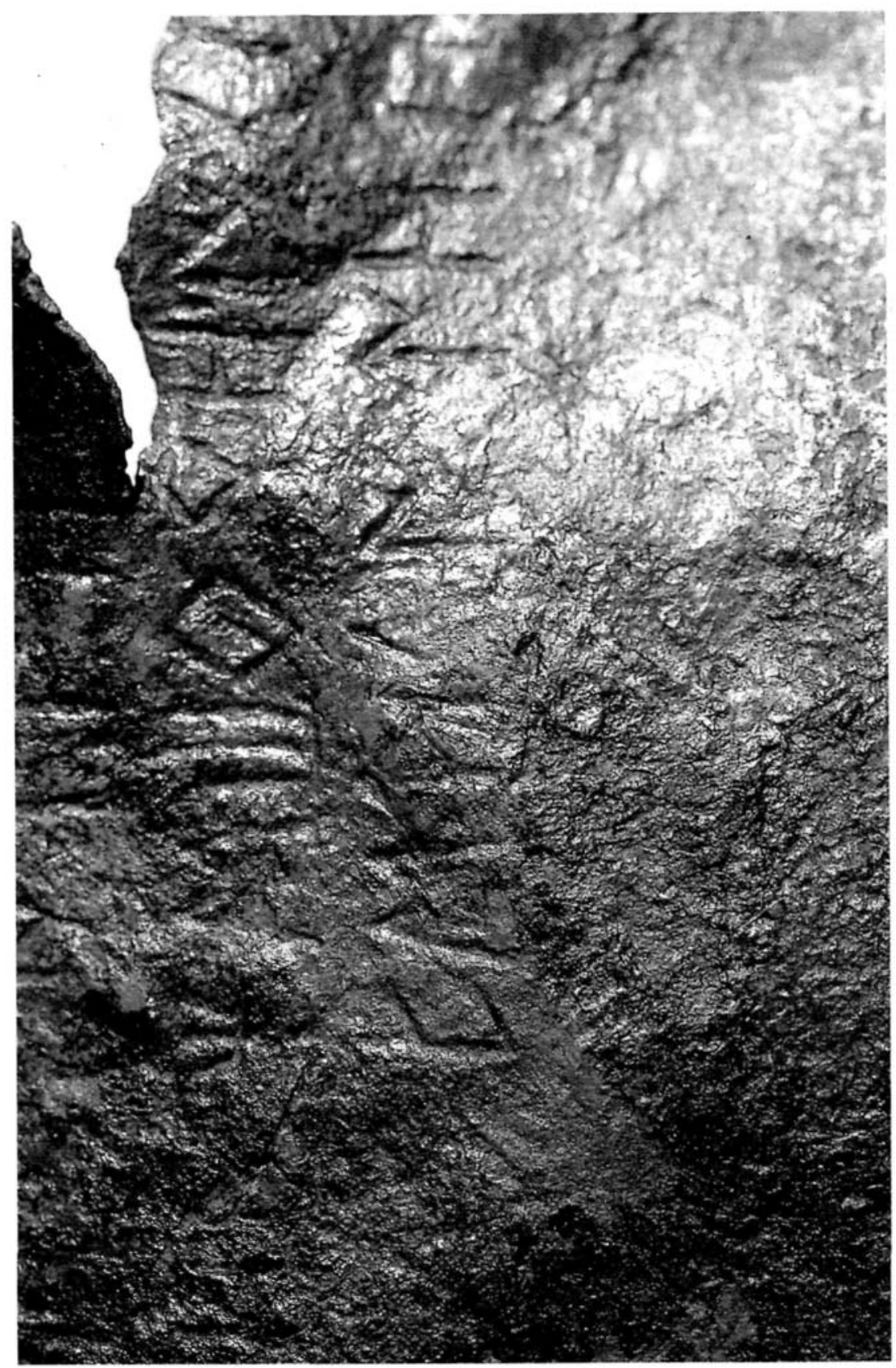

